\title{
Upward flame spread: heat transfer to the unburned surface
}

TSAI KUANG-CHUNG, JOHN TURNBULL, GAVIN WILL and DOUGAL DRYSDALE

Fire Safety Engineering Group

School of Civil and Environmental Engineering

University of Edinburgh

Edinburgh EH9 3LN, Scotland, UK

\begin{abstract}
An experimental programme was intended to analyse the heat feedback from a spreading wall fire to its unburned surface, one of the two important parameters determining its spread rate. The heat flux from PMMA fires was observed to be higher than those from previous investigations as plotted with normalised flame height $\left(X / X_{f}\right)$. However, very good consistency was performed with another study as a parameter $\dot{q}_{w o}$ "is introduced with heat flux plotted in another normalisation. The averaged heat flux, an important parameter used in upward flame spread modelling, was discussed and suggested to be around $15-20 \mathrm{~kW} / \mathrm{m}^{2}$. This is much lower than the commonly accepted $25-30 \mathrm{~kW} / \mathrm{m}^{2}$.
\end{abstract}

KEYWORDS: heat feedback, upward flame spread

\section{NOMENCLATURE}

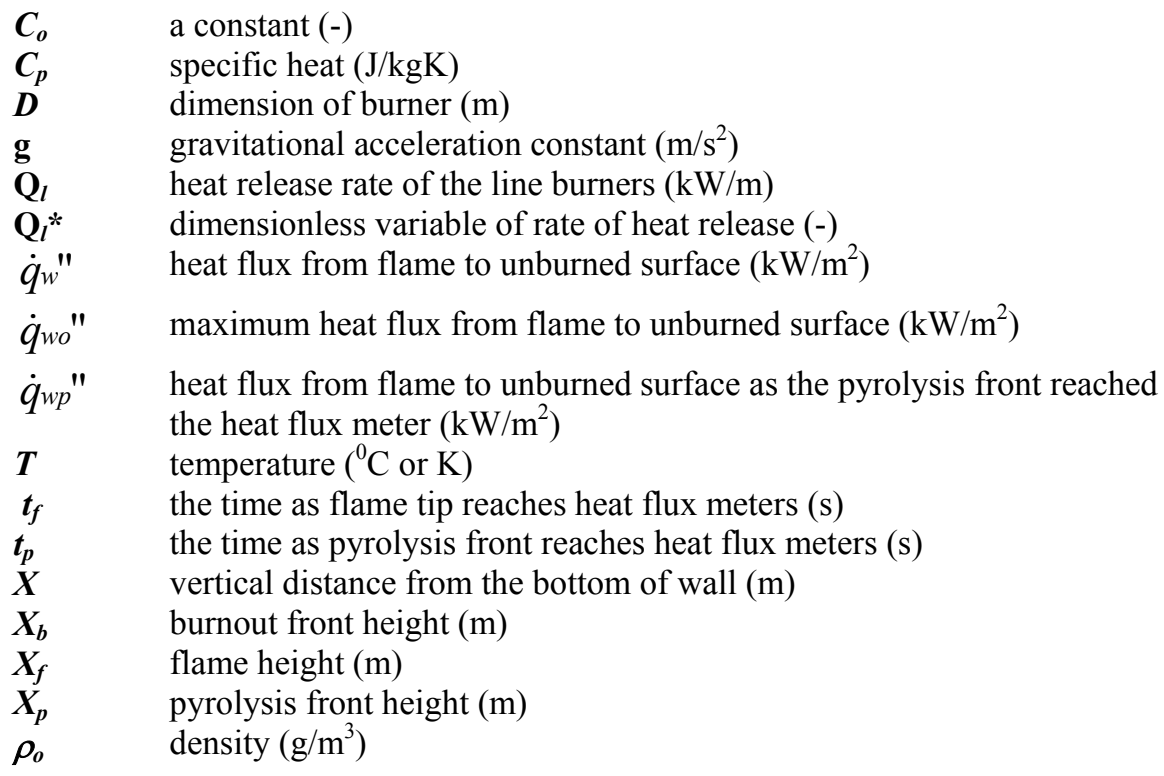




\section{INTRODUCTION}

Upward flame spread on vertical surfaces has attracted the attention of fire safety scientists and engineers for more than 30 years because it represents a particularly hazardous scenario which can produce very rapid fire development. Research has provided an understanding of the phenomenon by identifying the controlling mechanisms through mathematical formulations which are capable of simulation fire spread behaviour. Figure 1 is a schematic diagram of a flame spreading upwards on a vertical surface. The wall is undergoing pyrolysis (burning) in the region $\left(X_{p}-X_{b}\right)$, the flame tip reaches $X_{f}$ and below $X_{b}$ is the region of burnout. Fernandez-Pello and Hirano [1] pointed out that the heat transfer from the flame to the unburned fuel is the primary controlling mechanism. Delichatsios [2] further noted that the heat flux to the surface above the end of the pyrolysis region up to the flame tip (the preheating region $\left(X_{f} X_{p}\right)$ in Fig.1) and the extent of burning, i.e. the flame height in wall fires, are the two important parameters determining its flame spread rate.

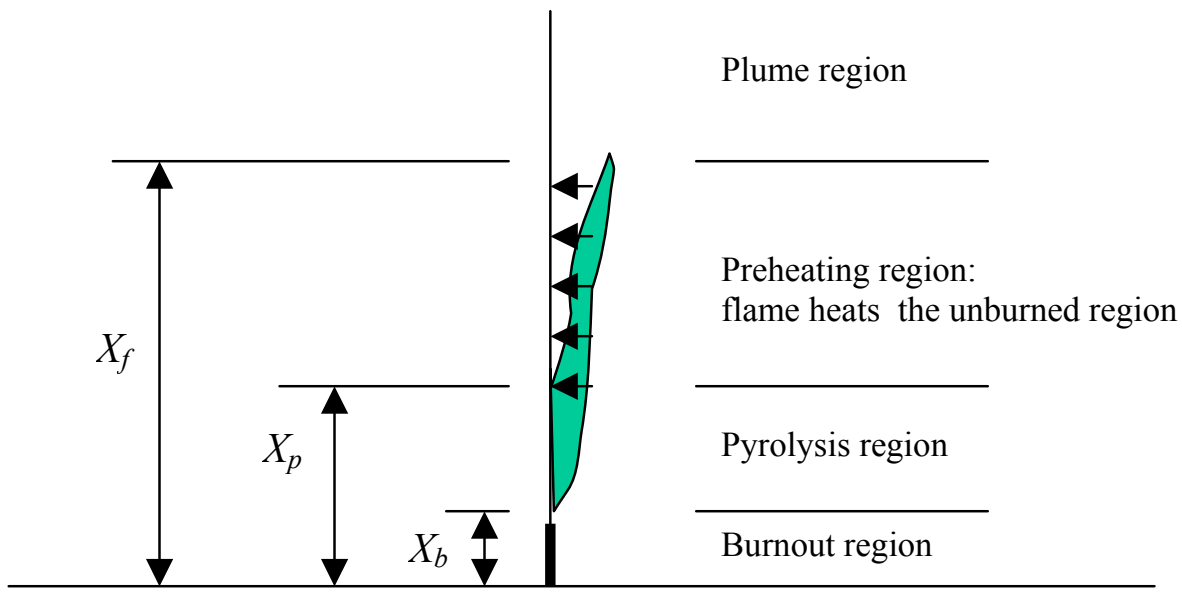

Fig. 1. Upward flame spread.

In this paper, the heat flux from the flame to unburned surface in the region $X_{f}-X_{p}$ is considered in detail. Measurements have been made from spreading PMMA wall fires and compared with previous investigations in which a similarity has been observed for a wide range of materials. In addition, the average heat flux in the preheating region is discussed as this is used in many upward flame spread models. 


\section{PREVIOUS EXPERIMENTAL INVESTIGATIONS}

One of the earliest sets of measurements of the wall flame heat flux distribution was made by Hasemi $[3,4]$ who used porous, methane line burners $(30 \mathrm{~cm}$ long and 3.7 or $8.2 \mathrm{~cm}$ wide) against the foot of a water-cooled isothermal wall, and a methane line burner (92 cm long and $7.5 \mathrm{~cm}$ wide) against a thermally thin wall. The isothermal wall had sidewalls, but no contiguous floor, while the thin wall had a contiguous floor but no sidewalls. Total heat fluxes were determined by means of Gardon gauges. Hasemi noted that the behaviour of flames near the line burners appeared to be different from the behaviour of flames from vertical fuels. However, his data appeared to be consistent with earlier work of others $[5,6]$. The heat flux data were found to lie in four distinct regions defined by the parameter $\dot{\boldsymbol{Q}}_{\boldsymbol{l}}^{* 2 / 3} \boldsymbol{D}=\left(\dot{\boldsymbol{Q}}_{\boldsymbol{l}} / \rho_{\boldsymbol{o}} \boldsymbol{C}_{\boldsymbol{p}} \boldsymbol{T}_{\boldsymbol{o}} \boldsymbol{g}^{1 / 2}\right)^{2 / 3}$. (This parameter is also used to correlate the visible flame heights of gas burner line fires.) The regions are:

(1) The lower part of the solid flame ( $\left.\boldsymbol{X} / \dot{\boldsymbol{Q}}_{l}^{* 2 / 3} \boldsymbol{D} \leq 1\right)$ in which $\dot{q}_{w}$ " tends to increase with height.

(2) The upper part of the solid flame $\left(1 \leq \boldsymbol{X} / \dot{\boldsymbol{Q}}_{\boldsymbol{l}}^{* 2 / 3} \boldsymbol{D} \leq 2.8\right)$ in which $\dot{q}_{w} "$ is apparently constant and appears to be a weakly increasing function of $\dot{\boldsymbol{Q}}_{l}^{*}$. The flame thickness is almost constant with height.

(3) The transition region $\left(2.8 \leq \boldsymbol{X} / \dot{\boldsymbol{Q}}_{l}^{* 2 / 3} \boldsymbol{D} \leq 10\right)$ in which the slope is the steepest among the four regions with all the data falling onto

$$
\dot{\boldsymbol{q}}_{\boldsymbol{w}}^{\prime \prime} \approx 45\left(\boldsymbol{X} / \dot{\boldsymbol{Q}}_{\boldsymbol{l}}^{* 2 / 3} \boldsymbol{D}\right)^{-5 / 2}
$$

(4) The plume region $\left(10 \leq \boldsymbol{X} / \dot{\boldsymbol{Q}}_{l}^{* 2 / 3} \boldsymbol{D}\right)$ in which the heat flux can be correlated by

$$
\dot{\boldsymbol{q}}_{\boldsymbol{w}}^{\prime \prime} \approx 2.5\left(\boldsymbol{X} / \dot{\boldsymbol{Q}}_{l}^{* 2 / 3} \boldsymbol{D}\right)^{-1.3}
$$

Quintiere et al. [7] also took heat flux measurements during their work on flame heights with $28.5 \times 28.5 \mathrm{~cm}$ burning surfaces (PMMA, rigid foam, carpet, flexible foam, aircraft panel and particle board). Heat flux meters were flush mounted on a contiguous watercooled plate which was located above the samples. Cooled side-plates were used to form a channel to preserve two-dimensionality of the boundary layer flow over the plate by preventing air entering the flame from the sides. They plotted their heat flux data in terms of $X / X_{f}$ and found them to be very consistent with Hasemi's data plotted in the same format $[3,4]$.

Brehob et al. [8] suggested another form for the correlation of $\dot{\boldsymbol{q}}_{w}^{\prime \prime}$ with height based on the data reported by Quintiere et al. [7] and Kim [9], viz.

$$
\frac{\dot{\boldsymbol{q}}_{w}{ }^{\prime \prime}}{\dot{\boldsymbol{q}}_{\boldsymbol{w}}{ }^{\prime \prime}}=\exp \left[-\boldsymbol{C o}\left(\frac{\boldsymbol{X}-\boldsymbol{X}_{\boldsymbol{p}}}{\boldsymbol{X} \boldsymbol{f}-\boldsymbol{X}_{\boldsymbol{p}}}\right)\right]
$$


where $\dot{q} w o "$ is the maximum heat feedback from flames to surface and the decay factor $C_{o}$ was determined to be 1.37 . The correlation allows $\dot{q}_{w}^{\prime \prime}$ to be determined from a single value of $\dot{q}_{w o}$ " which Brehob suggests may be regarded as a "fire property" of the wall lining material.

Table 1: Heat fluxes selected for the preheating region

\begin{tabular}{|c|c|c|}
\hline Modelling work & $\begin{array}{c}\text { Heat flux chosen } \\
\left(\mathrm{kW} / \mathrm{m}^{2}\right)\end{array}$ & Comments \\
\hline Saito et al. [9] & 25 & \\
\hline Mowrer and Williamson [10] & 30 & $\begin{array}{l}50 \text { for obtaining burning } \\
\text { duration time data }\end{array}$ \\
\hline Delichatsios et al.[11] & 30 & \\
\hline Delichatsios and Delichatsios [12] & 25 & \\
\hline Delichatsios and Chen [13] & 25 & \\
\hline Grant and Drysdale [14] & 20 & $\begin{array}{l}\text { averaged value during the } \\
\text { whole burning process }\end{array}$ \\
\hline Anderson et al. [15] & 35 & \\
\hline Kokkala et al. [16] & 25 & \\
\hline Qian and Saito [17] & 25 & \\
\hline Quintiere and Lee [18] & 25 & \\
\hline
\end{tabular}

\section{AVERAGED HEAT FLUX USED IN UPWARD FLAME SPREAD MODELLING}

A number of upward flame spread models have been developed in which the heat flux correlations of Hasemi [3, 4] and Quintiere et al. [7] have been used. However, to simplify the problem, most of these models [9-18] assume that $\dot{q}_{w}{ }^{\prime \prime}$ is constant over the preheating region, becoming zero at heights above $X_{f}$. Saito et al. [9] took $25 \mathrm{~kW} / \mathrm{m}^{2}$ as the constant heat flux exposed to which mass loss rate was obtained for their steady-state model. Good consistency has been shown with their PMMA flame spread rate measurement. Mowrer and Williamson [10] chose $30 \mathrm{Kw} / \mathrm{m}^{2}$ as the irradiance of the Cone Calorimeter under which material flammability properties were carried out. In addition, they chose $50 \mathrm{~kW} / \mathrm{m}^{2}$ to obtain the data of burning duration time. Delichatsios and co-workers [11] also adopted $30 \mathrm{~kW} / \mathrm{m}^{2}$ to be the fixed total flame heat flux of burning walls with flame heights shorter than $1.5 \mathrm{~m}$ in their Upward Fire Spread and Growth (UFSG) code, and considered radiative and convective heat transfer separately for flames higher than $1.5 \mathrm{~m}$. However, $25 \mathrm{~kW} / \mathrm{m}^{2}$ was used in their projects concerning PE/PVC cables [12] and charring materials [13]. In addition, Grant and Drysdale [14] took the average of the heat flux measured with their cardboard tests, and suggested 20 $\mathrm{kW} / \mathrm{m}^{2}$ to represent the heating scenario. Applying the Grant and Drysdale's model, Anderson et al. [15] used $35 \mathrm{~kW} / \mathrm{m}^{2}$ as the constant heat flux for hardboard, plywood and wallpaper covered wood surfaces. But $25 \mathrm{~kW} / \mathrm{m}^{2}$ was chosen again in the modelling work of Kokkala et al. [16] focusing on wood surface produces, Qian and Saito [17] 
analysing the difference of the heat feedback over vertical flat and corner walls and Quintiere and Lee [18] assessing ignitor and thickness effects on upward flame spread. Table 1 lists the representative heat flux chosen for these models.

\section{EXPERIMENTAL WORK}

Figure 2 shows in schematic form the experimental rig designed to allow samples to be ignited along the lower edge while in a horizontal position before being rotated into the vertical position at the start of the test.

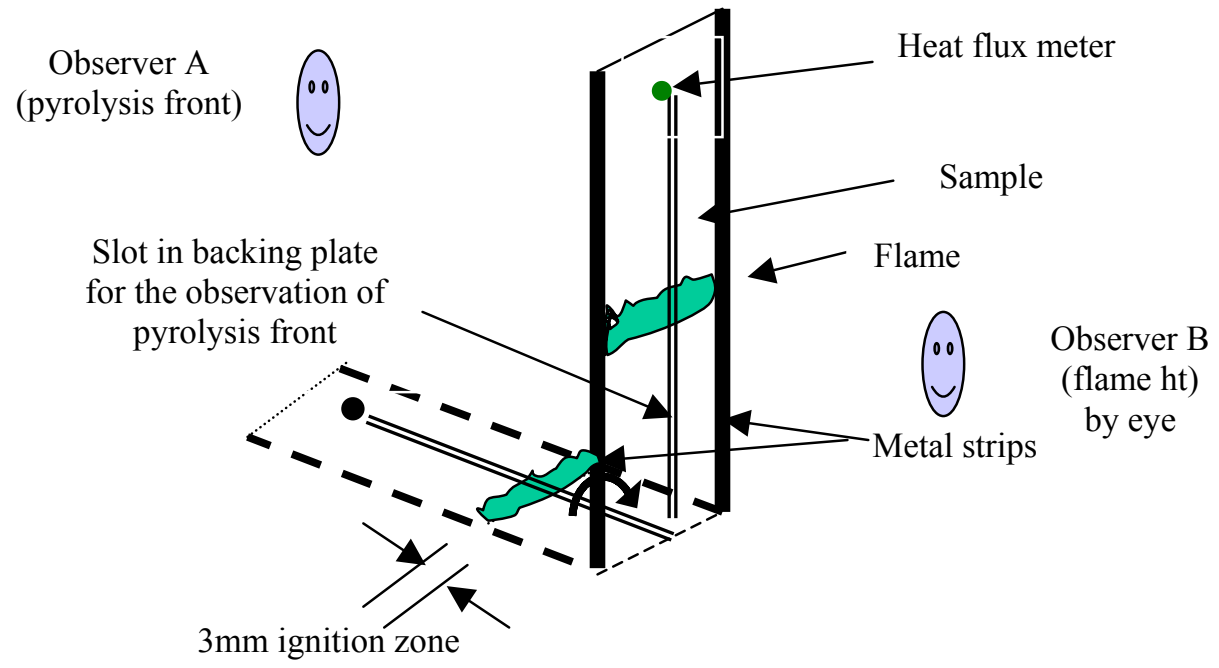

Fig. 2: Experimental rig used in this study. The dashed lines represent the horizontal position of the rig during ignition. It is then rotated into the vertical position (solid lines). The flame and pyrolysis heights were observed by eye from the front and rear of the rig.

The samples were cut from clear sheets of commercially available, bulk polymerised, high molecular weight PMMA, $6 \mathrm{~mm}$ thick. They were all $70 \mathrm{~mm}$ wide, but four different heights $(200,300,400$ and $500 \mathrm{~mm})$ were used. They were held against a $2 \mathrm{~mm}$ thick steel plate which not only prevented flame spreading up the back of the sample but also kept the rear face sufficiently cool to prevent distortion and slumping. The vertical edges of the samples were secured against the backing plate by two $3 \mathrm{~mm}$ thick mild steel strips which overlapped the samples by $5 \mathrm{~mm}$ on each long side: these also protected the vertical edges of the samples. A $5 \mathrm{~mm}$ wide slot was cut along the centreline of the backing plate to allow the pyrolysis front to be observed through the back of the sample, using the leading edge of the sub-surface bubbles as the marker. A water cooled Gardon heat flux meter, $25.4 \mathrm{~mm}$ diameter, was mounted flush with the sample surface, with its centre $20 \mathrm{~mm}$ from the top end of the sample. This was used to monitor the heat flux from the flame to the unburned surface during upward flame spread, but did not interfere with the flame spread process. 
A mild steel plate, $3 \mathrm{~mm}$ thick, was held against lower end of the sample, leaving an unprotected $3 \mathrm{~mm}$ strip of PMMA which was ignited uniformly across width of the sample using a hand-held butane-fuelled torch. The steel plate prevented extensive heating of the region ahead of the $3 \mathrm{~mm}$ ignition zone and was removed after ignition had been effected and immediately before the sample was raised into the vertical position. Measurements were taken by two people: observer A at the rear of the sample recorded the pyrolysis front as it advanced by $10 \mathrm{~mm}$ steps while observer B recorded the flame height visually at each corresponding time. The flame height was taken as the average, as determined by eye. The rate of upward spread was sufficiently slow for it to be assumed that the flame was in a quasi-stationary state.

\section{RESULTS AND DISCUSSION}

The experiments were designed to provide data on the early stages of fire growth on a vertical surface. The results are relevant to combustible surfaces exposed to localised ignition sources and not for combustible linings exposed to large diffuse sources. This would require work on a larger scale.

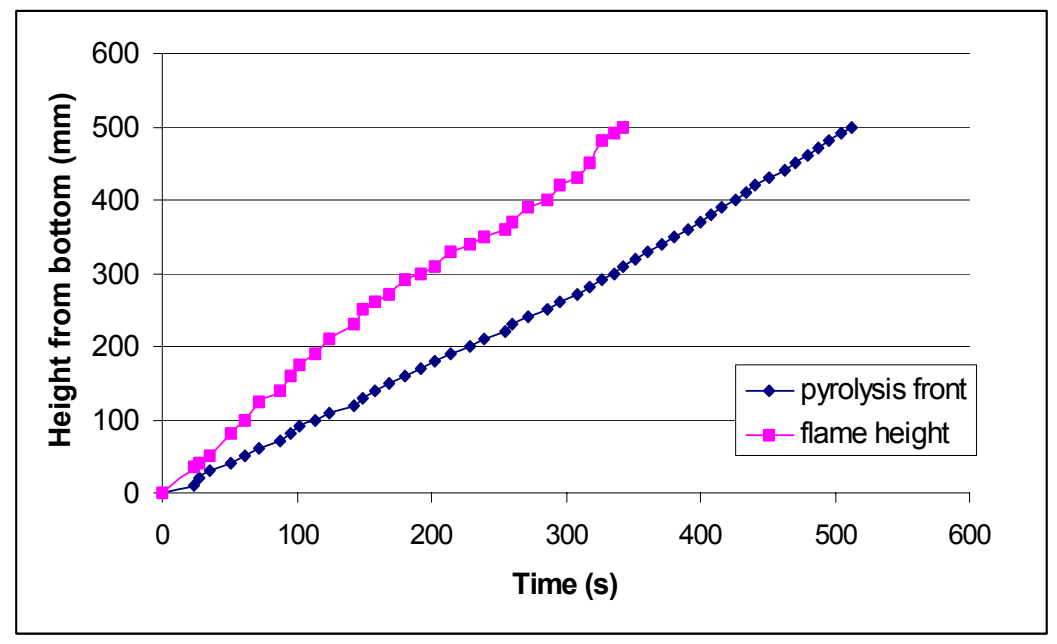

Fig. 3: A typical flame height and pyrolysis front measurement on a $500 \mathrm{~mm}$ height PMMA sample as a function of time. The gradient of the pyrolysis front line gives the rate of spread.

Figure 3 shows typical measurements of the pyrolysis front and flame height on a 500 mm high PMMA sample. Figure 4 shows heat flux measurements (average of three tests each) $20 \mathrm{~mm}$ from the top edge for 200, 300, 400 and $500 \mathrm{~mm}$ high samples. The quantities $t_{f}$ and $t_{p}$ can be identified as the times when the flame tip and pyrolysis front reach the heat flux meter, respectively. The difference $\left(t_{p}-t_{f}\right)$ then represents the time during which the preheating region is exposed to a direct heat flux from the flame (Figure 1). The heat fluxes at $t_{f}$ and $t_{p}$ for different heights of sample are identified on Figure 4 and are listed in Table 2. Figure 4 also shows that the maximum heat flux occurs just behind the pyrolysis fronts, i.e. at the onset of steady burning. The average maximum heat flux was approximately $38 \mathrm{~kW} / \mathrm{m}^{2}$. 


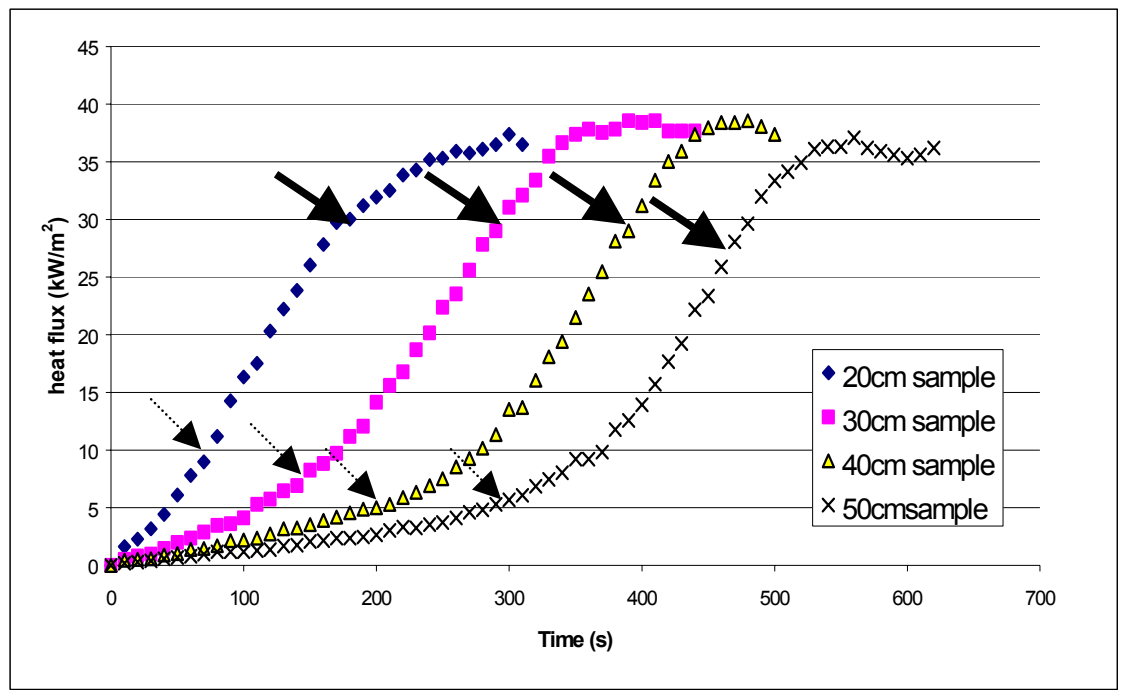

Figure 4: Variation of heat flux $20 \mathrm{~mm}$ from the top of the 200, 300, 400 and $500 \mathrm{~mm}$ samples (no sidewalls). ( $\rightarrow$ marks the time when the flame tips reach the heat flux meter;

$\rightarrow$ indicates when the pyrolysis fronts reached the heat flux meters.)

Figure 5 shows the heat flux distribution of the spreading PMMA wall fires plotted as a function of height $(X)$ normalised against the flame height. The data from Quintiere et al. [7] are included for comparison. It can be seen that these are lower then the measurements from this study. However, there is a significant difference between the two sets of experiments: in this study the data were obtained by measuring the heat fluxes during upward flame spread on vertical PMMA samples up to $500 \mathrm{~mm}$ high, while Quintiere et al. [7] made their measurements during the steady state burning of $285 \mathrm{~mm}$ square samples with the heat flux meters flush mounted on a water-cooled copper plate above the burning area. This will have a cooling effect on the boundary layer flow and consequently reduce the heat flux measured at the heat flux meters.

\begin{tabular}{|c|c|c|c|}
\hline $\begin{array}{c}\text { Sample height } \\
(\mathbf{m m})\end{array}$ & $\begin{array}{c}\text { Heat flux at flame } \\
\text { tip }\left(\mathbf{k W} / \mathbf{m}^{\mathbf{2}}\right)\end{array}$ & $\begin{array}{c}\text { Heat flux at pyrolysis } \\
\text { front } \mathbf{( k W / \mathbf { m } ^ { 2 } )}\end{array}$ & $\begin{array}{c}\text { Average value } \\
\left(\mathbf{k W} / \mathbf{m}^{\mathbf{2}}\right)\end{array}$ \\
\hline 200 & 9.6 & 31 & 20 \\
\hline 300 & 8.8 & 30 & 19.5 \\
\hline 400 & 6.5 & 29 & 18 \\
\hline 500 & 6.4 & 29 & 18 \\
\hline
\end{tabular}

Table 2: Heat fluxes at the flame tip and the leading edge of the pyrolysis front. The right hand column gives the average value over the pre-heating region. 


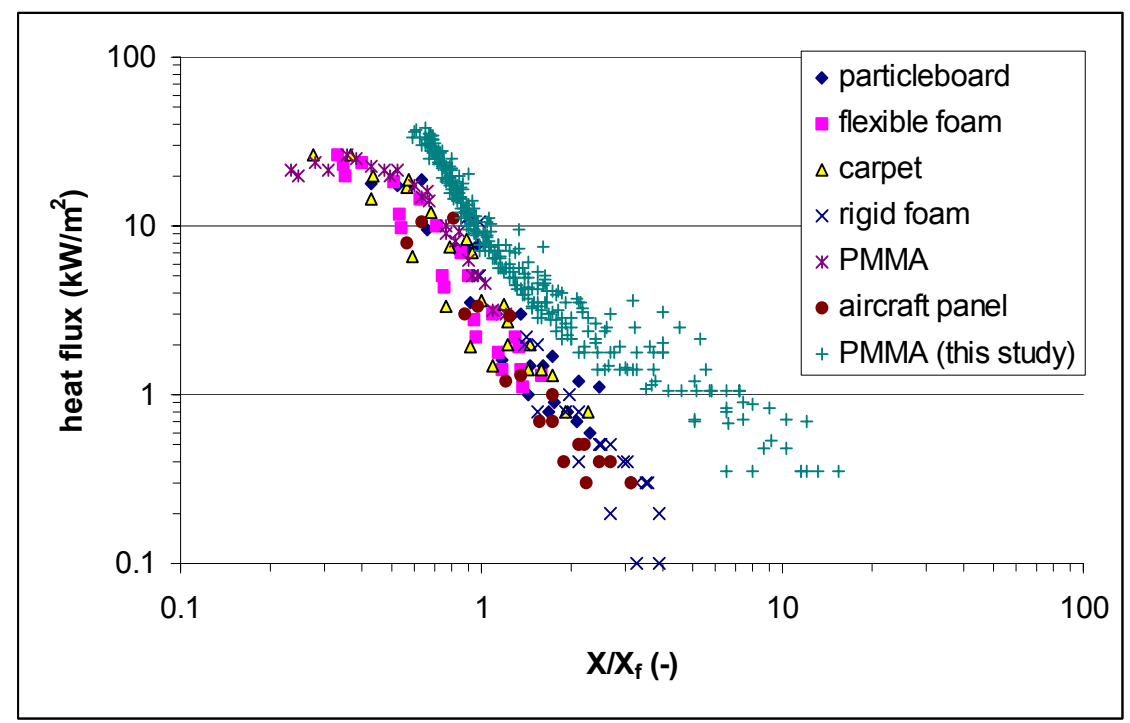

Fig. 5: The heat flux distribution of measurements from Quintiere et al. [7] and from the spreading PMMA flames plotted against $\left(X / X_{f}\right)$.

In Figure 6, the heat flux distributions shown in Figure 5 are plotted in a form suggested by Brehob et al. [8], namely, as $\dot{\boldsymbol{q}}_{w}^{\prime \prime} / \dot{\boldsymbol{q}}_{w p}^{\prime \prime}$ vs $\left(\boldsymbol{X}-\boldsymbol{X}_{\boldsymbol{p}}\right) /\left(\boldsymbol{X}_{\boldsymbol{f}}-\boldsymbol{X}_{\boldsymbol{p}}\right)$, where the heat flux $\dot{\boldsymbol{q}}_{\boldsymbol{w} \boldsymbol{p}}^{\prime \prime}$ corresponds to $t_{p}$ rather than the final (maximum) value $\dot{\boldsymbol{q}}_{\boldsymbol{w} \boldsymbol{o}}^{\prime \prime}$ in the pyrolysis regions (Figure 1) as in Equation 3. The best-fit function is:

$$
\frac{\dot{\boldsymbol{q}}{ }^{\prime \prime}}{\dot{\boldsymbol{q}}_{\boldsymbol{w} p}{ }^{\prime \prime}}=0.21\left[\frac{\boldsymbol{X}-\boldsymbol{X} \boldsymbol{p}}{\boldsymbol{X} \boldsymbol{f}-\boldsymbol{X} \boldsymbol{p}}\right]^{-0.81}
$$

The correlation ( $\mathrm{r}^{2}$ equal to 0.927$)$ is in a different format from that of Brehob et al. [8] (Equation 3), however, good agreement can be seen for $\left[\left(X-X_{p}\right) /\left(X_{f}-X_{p}\right)\right]<1$. 


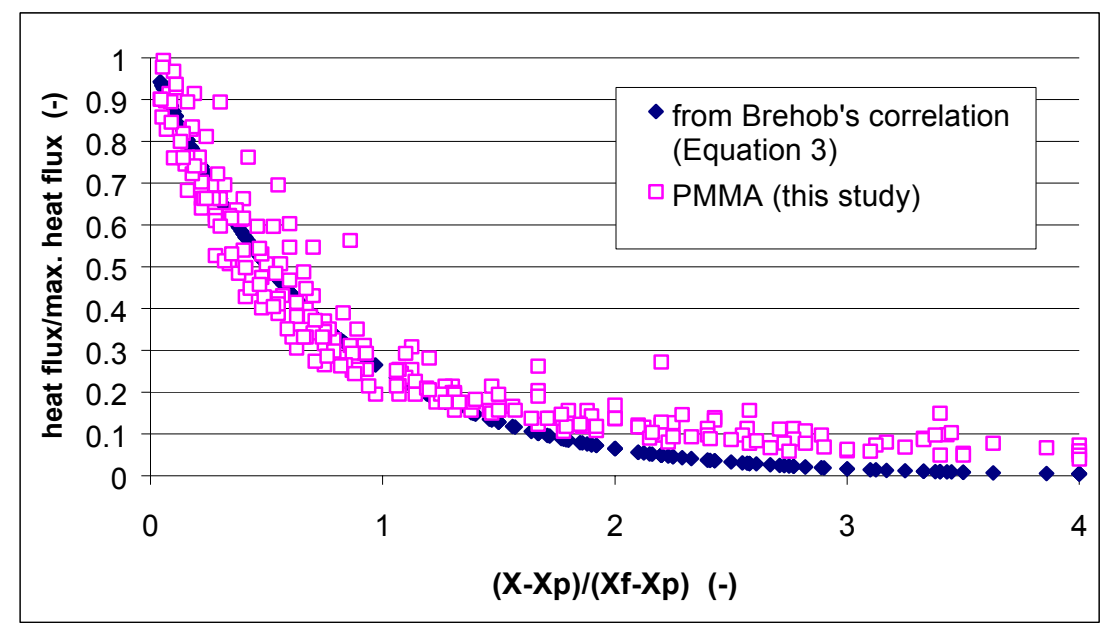

Fig. 6: The comparison of heat flux distributions following Brehob et al. [8] (Equation 3 ) and in this study. (Brehob et al. [8] used the final heat flux $\dot{q} w o$ " to be the maximum one, but in this study the heat flux as the pyrolysis front reached the heat flux meter $\dot{q} w p$ "was used.)

In upward flame spread models, it is important to use as input data the best available representation of heat transfer to the preheating region. Ideally, a function such as Equation 4 should be used, but a simpler approach has been generally adopted. This has been dictated partly by the availability of data from the Cone Calorimeter which apply to a single (constant) heat flux for both the time to ignition and rate of heat release measurements. Table 1 shows the range of heat fluxes used by different investigators to obtain $t_{i g}$ and RHR data (and apply to their models). With the exception of Grant and Drysdale [14], all are $25 \mathrm{~kW} / \mathrm{m}^{2}$ or above. However, the current data show that the heat flux varies from c. $7.8 \mathrm{~kW} / \mathrm{m}^{2}$ at the flame tip to c. $29.8 \mathrm{~kW} / \mathrm{m}^{2}$ at the leading edge of the pyrolysis zone. It would seem appropriate to use $t_{i g}$ and RHR data obtained in the Cone Calorimeter at an average value less than $20 \mathrm{~kW} / \mathrm{m}^{2}$. The heat flux distributions derived by Hasemi [5,6], Quintiere et al. [7], Brehob et al. [8] and in this study are similar enough to suggest that they may be material-independent. This offers the possibility that a single representative heat flux could be used for a range of materials, taking the average of the highest and lowest heat fluxes measured in the preheating region (Figure 1). This would provide a value of c. $18.8 \mathrm{~kW} / \mathrm{m}^{2}$, which is much lower than the values chosen by others (Table 1).

Further support for this conclusion is to be found in a recent paper by Tsai and Drysdale [19]. They point out that it is unreasonable to use the RHR data obtained from the Cone Calorimeter at the same heat flux at which $t_{i g}$ was determined. After a vertical surface has been ignited (and the source of ignition removed), the process is self-sustaining. The rate of burning of the area below the pyrolysis front is determined by heat feedback from the established flame. In reference [19] it is shown that excellent agreement is obtained between experimental data and prediction by Grant and Drysdale's model [14] when $t_{i g}$ at 
$15 \mathrm{~kW} / \mathrm{m}^{2}$ and the RHR with no imposed heat flux were used as input data. These data were obtained by using a non-standard procedure with the Cone Calorimeter in which the cone heater was removed immediately after ignition [19].

\section{CONCLUSION}

Measurements of the heat feedback from upward spreading PMMA fires were carried out and compared with previous experimental correlations. Fairly good agreement was observed. An important parameter, representative heat flux within the preheating region of upward flame spread used in many wall fire models, was discussed. A lower value than commonly accepted ones was suggested.

\section{REFERENCES}

1. Fernandez-Pello AC and Hirano T, Controlling mechanisms of flame spread, Combustion Science and Technology, Vol. 32, pp.1-31, 1983

2. Delichatsios MA, Flame heights in turbulent wall fires with significant flame radiation, Combustion Science and Technology, Vol. 39, pp. 195-214, 1984

3. Hasemi Y, Thermal modeling of upward wall flame spread, Fire Safety ScienceProceedings of the First International Symposium, pp. 87-96, 1985

4. Hasemi Y, Experimental wall flame heat transfer correlations for the analysis of upward flame spread, Fire Science and Technology, Vol.4, No.2, pp. 75-90, 1984

5. Ahmad T. and Faeth GM, Turbulent wall fires, $17^{\text {th }}$ Symposium (International) on combustion, pp. 1149 1160, 1978

6. Liburdy JA and Faeth GM, Heat transfer and mean structure of a turbulent thermal plume along a vertical isothermal wall, Journal of Heat Transfer, Vol.100, pp. 177183,1978

7. Quintiere J, Harkleroad M and Hasemi Y, Wall flames and implications for upward flame spread, Combustion Science and Technology, Vol. 48, pp. 191-222, 1986

8. Brehob EG, Kim CI and Kulkarni AK, Numerical model of upward flame spread on practical wall materials, Fire safety Journal, Vol. 36, pp.225-240, 2001

9. Saito K, Quintiere JG and Williams FA, Upward turbulent flame spread, Fire Safety Science- Proceedings of the First International Symposium, pp. 75-86, 1985

10. Mowrer FW and Williamson RB, Flame spread evaluation for thin interior finish materials, Fire Safety Science- Proceedings of the Third International Symposium, pp. 689-698, 1991

11. Delichatsios MM, Mathews MK and Delichatsios MA, An upward fire spread and growth simulation, Fire Safety Science- Proceedings of the Third International Symposium, pp. 207-216, 1991

12. Delichatsios MA, and Delichatsios MM, Upward flame spread and critical conditions for PE/PVC cables in a tray configuration, Fire Safety ScienceProceedings of the Fourth International Symposium, pp. 433-444, 1995

13. Delichatsios MA and Chen Y, Flame spread on charring materials: numerical predictions and critical conditions, Fire Safety Science- Proceedings of the Fourth International Symposium, pp. 457-468, 1995

14. Grant $\mathrm{G}$ and Drysdale D, Numerical modelling of early flame spread in warehouse fires, Fire Safety Journal, Vol.24, pp. 247-278, 1995

15. Anderson M, McKeever C, Pehrson R and Barnett J, An experimental study of upward flame spread on cellulosic materials, InterFlam'96, pp.169-178, 1996 
16. Kokkala M, Baroudi D and Parker WJ, Upward flame spread on wooden surface products: experiments and numerical modelling, Fire Safety Science- Proceedings of the Fifth International Symposium, pp. 309-320, 1997

17. Qian C and Saito K, An empirical model for upward flame spread over vertical flat and corner walls, Fire Safety Science- Proceedings of the Fifth International Symposium, pp. 285-296, 1997

18. Quintiere JQ and Lee CH, Ignitor and thickness effects on upward flame spread, Fire Technology, Vol.34, No.1, pp.18-38, 1998

19. Tsai K-C and Drysdale D, Using Cone Calorimeter data for the prediction of fire hazard, Fire Safety Journal, accepted for publication. 